o'CONNOR, S. I 966. Satingpra: an expanded chronology, Fournal of the Malaysian Branch of the Royal Asiatic Society, xxxix, 137-44.

1972. Hindu gods of peninsular Siam (Ascona).

STARGARDT, J. I972. The ceramic industry of Southern Thailand in the Srivijayan period (in English and Thai), Archaeology, Journal of Silapakorn University, Bangkok (October), - . 1973a. Southern Thai waterways: archaeological evidence on agriculture shipping and trade in the Srivijayan period, $M a n$, viII (1), 5-29.

$1973 \mathrm{~b}$. Un rapport préliminaire sur la découverte d'un centre industriel de céramique de l'époque çrivijayan dans le sud de la Thaĩlande, Arts Asiatiques, in press.

\title{
Earth sciences in archaeology and history
}

Professor N. N. Ambraseys of the Engineering Seismology Section of the Department of Civil Engineering, Imperial College of Science and Technology, London, has sent us the following note of warning.

During the last decade there has been a welcome rapprochement between archaeologists, historians and earth scientists. There have been a number of very interesting publications by archaeologists which have considered recent advancements in earth sciences and which have tried, with various degrees of success, to evaluate these developments for archaeology.

Equally important, almost an indispensable tool, is the use of history and archaeology in earthquake prediction studies. Let me explain.

Almost all estimation of seismicity is probabilistic and the probabilities may be computed from observed occurrences of earthquakes. Yet the length of time covered by modern instrumental seismology is negligibly short when compared with the geological time-scale involved in earthquake processes. Thus, in spite of the considerable volume of data for earthquakes in the present century, a much longer period of observation is needed to permit a meaningful statistical treatment. This can be achieved only by resorting to data for earthquakes prior to 1900 and by choosing for study seismic regions where the time-scale is long and the recorded data are good (Ambraseys, 1962, 895; Wilson, 1972, 59).

A systematic study of early earthquakes began in 1960 at this College and it is still in progress. The region selected for study comprises the Eastern Mediterranean Basin which has a very long and well documented history. Already, there have been significant results both of geophysical and historical importance and
I would like to mention three points which have emerged (Ambraseys, I97I, 375).

The first point concerns the interpretation of early earthquakes. Modern man-made structures differ in many respects from old ones and to judge future damage from centuryold case histories can be seriously misleading. For instance, a large distant earthquake fifteen centuries ago would have caused practically no structural damage to Constantinople, Antioch or Nicaea; the same earthquake today would cause damage to a number of modern, more flexible structures in these cities.

The second point concerns the assessment of seismicity of a particular region using extant structures of old age. It is usually considered rather improbable that early structures, liable to damage by earthquakes, could stand for many centuries in seismic regions. The mere fact that quite a few early buildings are still to be found in a state of tolerable preservation in various parts of the world has led to the belief that these places have been free from destructive earthquakes. But our evidence shows that this is not the case. The early buildings that are still standing have, in fact, during their life-time, been subjected to a number of destructive earthquakes and they have survived through a process of natural selection. They are a very small fraction of the total number of structures that existed in early times and they represent today a sample of structures of the best final design and construction, achieved through the ages by trial-and-error techniques or by chance. Thus, the mere fact that a few early monuments are still standing on various sites in Greece, Turkey, Iran or in Syria should not be taken to mean that these sites have been free from damaging earthquakes. 


\section{ANTIQUITY}

Perhaps it is one of our most interesting findings that the lasting effects of major earthquakes and volcanic eruptions during the past twenty-four centuries would not seem to have been very significant. Soon after a major earthquake vested interests of the inhabitants led them to act once again with disregard for the prospect of further such calamities. Earthquakes in the past twenty-four centuries have had little, if any, serious influence on historical developments in the Middle and Near East. They did often account for the premature decline of a local economy or for a crisis in local human affairs. But they have never caused the ruin of a culturally advanced state, far less the end of a civilization. In contrast with wars, epidemics and other long-lasting calamities, which have serious and prolonged effects, earthquakes and volcanic eruptions, no matter how large, seem to have had little or no longterm impact on Man. It may be that men react to the inevitable hazard in a special way, distinct from their reaction to the preventable hazard. Personal, political, religious and economic interests seem to overshadow, and in some cases suppress, the lessons to be learnt from destructive earthquakes. Yet modern writers have attempted to use earthquakes or volcanic eruptions to account, invoking the idea of deus ex machina, for gaps in the sequence of civilizations and for movements of peoples (Schaeffer, 1948), hypotheses for which we can find absolutely no justification.

Already this increasing interest in, and alarm about, the use and misuse of earth sciences by historians and archaeologists on the one hand (Luce, I969; Marinatos, 1939 and I968; Page, 1970; Pomerance, 1970; 1971) and of archaeology or history by earth scientists on the other (Galanopoulos and Bacon, 1969; Mavor, 1969) has manifested itself in a number of publications and also in recent reviews in ANTIQUITY (1970, 75 and $163 ; 1971,154)$.

Like any other broadly defined subject it is fraught with danger. One obvious danger, which we must strive to avoid, arises from the situation that some of the most popular interdisciplinary theories are promulgated by authors who have had little, if any, direct research or field experience with all the branches of science or art they invoke. Some of the scientific material is fresh and pertinent, some out-of-date or at second hand, some oversimplified and misleading. Perhaps scientists, being hardened trespassers and also already acquainted with much of the scientific material, will, more than most, find frequent cause for irritation in the premises of these theories. There, solid fact is spiced with shrewd comment and one finds the occasional sweeping generalization that most sudden ends of civilizations in the Mediterranean Basin were due to earthquakes and volcanic eruptions, as well as odd snatches of Plato's Critias and Timaeus; the scientist will almost certainly find the treatment puzzling.

I think that it is not sufficient for the archaeologist or the earth scientist to receive at third hand some information from another discipline and then use it in his theory, without understanding how this information was obtained and what it really means. In addition, it is necessary to develop an intimate knowledge of the intricacies and subtleties of the sciences he uses.

It is perhaps appropriate, if somewhat sad, that reviews of some of these interdisciplinary publications that have appeared in ANTIQUITY should not be more thought-provoking. There are of course no polemics in these reviews, but equally no real discussion of science as a tool in archaeology. When your reviewer argues that the best archaeological tool is the shovel as compared to magnetic and refraction techniques because the 'spade works well and does not speak', it is not entirely clear whether he writes for the benefit of the layman, the specialist or for himself and for the "amity of nations' (1970, 75). But this is to a degree inevitable, and also understandable, since here authors and reviewer consciously venture into unfamiliar fields.

It is precisely to this danger that I wish to draw attention.

AMBRASEYS, N. 1962. Data for the investigation of the seismic sea-waves in the Eastern Mediterranean, Bull. Seismological Soc. Amer., III, 895 .

r97I. Value of historical records of earthquakes, Nature, vol. 232, no. 5310, 375-9. 


\section{NOTES AND NEWS}

GALANOPOULOS, A. and E. BACON. 1969. The truth behind the legend (London).

LUCE, J. v. 1969. The end of Atlantis, new light on an old legend (London).

marinatos, s. r939. The volcanic destruction of Minoan Crete, Antiquity, xIII, 425-39.

1968. The volcano of Thera and the Aegean civilization, Proc. 2nd Intern. Cretological Congress, I, 198.

Mavor, J. W. 1969. Voyage to Atlantis (London).

PAGE, D. L. 1970. The Santorini volcano and the desolation of Minoan Crete, Soc. Promotion Hellenic Studies, Suppl. paper no. I 2 (London).

POMERANCE, L. 1970. The final collapse of Santorini (Thera): 1400 BC or I 200 BC? Studies in Mediterr. Archaeology, xxvi (Goteborg).

1971. The need for guide lines in interdisciplinary meetings, $A \mathcal{F} A$, LXXV, 428-31.

SCHAEFFER, C. F. 1948. Stratigraphie comparée et chromologie de l'Asie occidental, vol. I (Oxford).

WILSON, T. J. I972. Mao's almanac; 3000 years of earthquakes, Saturday Reviez, Feb. 19, p. 59.

\section{The Faussett collection at Liverpool}

PLATE XXXII

The Faussett collection of Anglo-Saxon antiquities excavated in Kent between 1760 and 1773 is housed in the City of Liverpool Museums. Following a suggestion by Mrs Webster, of the Department of Medieval and Later Antiquities at the British Museum, Miss Dorothy Slow and Mrs Margaret Warhurst, Keeper and Assistant Keeper of Archaeology respectively in the City of Liverpool Museums, have sent us this note.

In the spring of $197 \mathrm{x}$, during a check on files of old correspondence, a letter was noticed from a descendant of the Reverend Bryan Faussett listing documents still retained by the family and mentioning portraits of Faussett and his wife by Thomas Hudson. The letter had been written fourteen years before and attempts to reach the address on it were unsuccessful, but with the help of the local police constable, we eventually traced the writer of the letter, who was most co-operative and promised to send us any documents he felt might be of interest, and to have the portraits cleaned and subsequently photographed for us. A suitcase of documents of varying importance as far as the Liverpool collection is concerned, but all of great interest, duly arrived together with excellent colour photographs of the portraits. The portraits of Bryan and Elizabeth
Faussett are the work of Thomas Hudson completed in $175^{8}$ at a cost of $£ 3015 \mathrm{~s}$ od including frames and packing box. Black-andwhite prints are reproduced (PL. XXXII).

The most important document is what may well be the earliest archaeological field notebook to survive. It records the excavations carried out in 1772 at Sibertswold, Barfriston, Kingston and Iffin Wood. The entries have been crossed out, presumably as Faussett entered each one in the six vellum-bound 'site-reports' which came with the finds, as part of the Faussett Collection, to the Museum in 1867. There are, however, a small number of sketches in the field notebook, which were not included in the bound volumes, and these may well prove to be important in re-attributing some of the ironwork which has survived without details of provenance and grave group.

On the inside back page of the field notebook Faussett noted the wages of some of the labourers he employed to excavate the cemeteries. These expenses are not entered in his daybooks which otherwise appear to contain meticulous records of all his income and expenditure. Unfortunately, no more field notebooks seem to have survived for the other years when Faussett was carrying out excavations in Kent.

\section{Estimating the duration of cultures}

The author of this note is Mrs Barbara Ottaway, a graduate in the Department of Archaeology, University of Edinburgh, now engaged in research. In a recent publication, the practice was recommended of grouping together all $\mathrm{C}_{14}$ dates published for a single culture, and expressing their scatter in terms of the interquartile range (Ottaway, r973). This avoids giving excessive weight to outlying dates, and a predicted advantage is that the median and the quartile dates should be little disturbed by the incorporation of new dates as they become 